\title{
p̈h

\section{Rituales y festejos en el valle de los Pedroches. Imágenes simbólicas de un territorio de frontera}

Juan Agudo Torrico | Departamento de Antropología Social, Universidad de Sevilla

URL de la contribución <www.iaph.es/revistaph/index.php/revistaph/article/view/3515>

\section{RESUMEN}

Históricamente la comarca del valle de los Pedroches ha sido un territorio de frontera interior, entre las tradiciones culturales castellanas y andaluzas. Es por ello que muchas de las expresiones culturales que caracterizan a la comarca, mientras que son compartidas con los territorios manchegos y extremeños circunvecinos, apenas si se encuentran en otros lugares de Andalucía.

En semejante contexto, los rituales que perviven en la comarca constituyen un ejemplo relevante del mencionado pasado y proceso histórico. El análisis que realizamos parte de este hecho para centrarnos en aquellos aspectos que consideramos que dotan de una mayor singularidad etnográfica a su sistema ritual: el papel que han jugado las numerosas ermitas y santuarios en la configuración del territorio simbólico; significación de sus romerías como ejes centrales de este sistema ritual; y particularidades del modelo de hermandades militares que ha caracterizado al sistema organizativo y procesos rituales en muchos de sus poblaciones.

\footnotetext{
Palabras clave

Actividades de interés etnológico | Andalucía | Antropología | Córdoba (Provincia) | Festividades cristianas | Influencia cultural | Patrimonio cultural | Rituales festivos | Valle de los Pedroches (Córdoba) |
} 


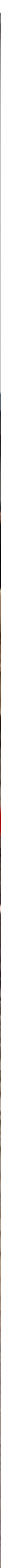

Santa Lucía en Villanueva del Duque | foto Fondo Gráfico IAPH 
La comarca que hoy conocemos como valle de los Pedroches ha sido a lo largo de buena parte de su historia una tierra de frontera interior. $Y$, por lo tanto, de territorio de encuentro, de intercambio de expresiones y prácticas culturales. Y así sigue siendo sentida hoy en día, depositaria de unos rasgos culturales que se fueron conformando básicamente en el trascurso de la Baja Edad Media; cuando, al tiempo que dejaba de pertenecer al AlÁndalus, se afianzaba como límite de los nuevos reinos cristianos que, con el paso del tiempo, terminarían por convertirse en la España de las autonomías del presente. De este modo, el valle de los Pedroches se convierte en la comarca más septentrional de Andalucía, penetrando como punta de lanza entre Extremadura y Castilla la Mancha; y, en contrapartida, también se transforma en el límite meridional de estos otros territorios.

En la práctica, historia e imaginarios colectivos han concluido por dotar al valle de los Pedroches de un notable particularismo cultural, con lo que su actual adscripción jurídico-administrativa a la autonomía andaluza contrasta con un sentimiento de identidad en el que aflora, y se reseña con frecuencia, la fuerza que siguen teniendo los rasgos culturales identificados con unas no menos imaginarias culturas extremeña y manchega: habla, arquitectura, gastronomía, paisajes culturales, música,...

Sus rituales vendrían a ser un magnífico ejemplo de esta paradoja de cruces de identidades. Como después veremos, hay rituales y sistemas organizativos que no rebasaron los límites meridionales de la comarca; pero en otros aspectos poco o nada diferencia las formas de expresión festivo-ceremoniales que encontramos en la comarca, de los rituales que podemos observar en cualquier otro lugar de Andalucía, o de las dinámicas de transformación que les afecta.

Así, hoy en día, en el conjunto de las diecisiete poblaciones que se distribuyen por su territorio, encontraremos un complejo y rico sistema ritual. La

Auto de los Reyes Magos en El Viso

| fotos Fondo Gráfico IAPH
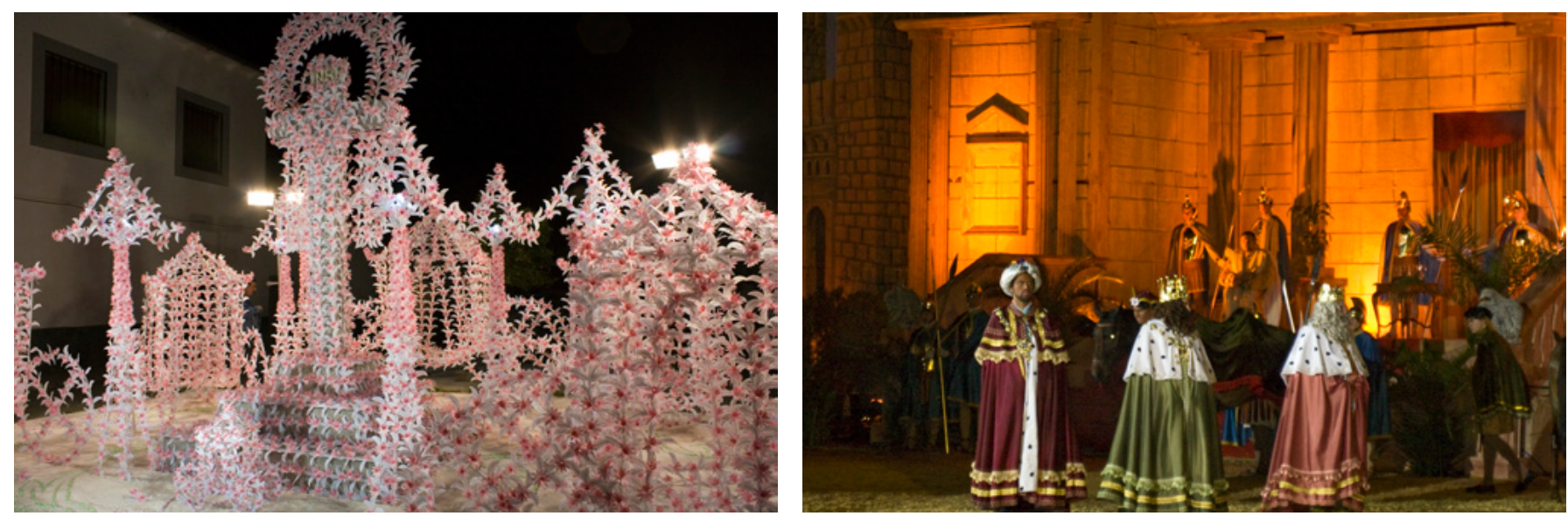
vida y economía de sus pobladores siempre ha estado centrada en la actividad agroganadera. Por ello, como en tantos otros lugares, su ciclo festivo va a estar pautado por el ritmo de las estaciones, acompasando los tiempos de descansotrabajo al ritmo de las labores en el campo y benignidad climatológica.

Sin que nos podamos detener en un análisis más pormenorizado, las fiestas de invierno, entroncadas con tradiciones más castellanas que andaluzas, están bien representadas por los candelorios que se celebran en las calles de buena parte de sus poblaciones con motivo de la Virgen de la Candelaria (en torno al dos de febrero), recuperados con vigor desde las últimas décadas del siglo XX. También son numerosos y diversos los festejos que celebran San Sebastián, advocación que llegó a contar con ermitas en al menos siete de sus localidades. Y como referencia emblemática de la propia comarca, en El Viso se sigue representando uno de los más antiguos autos sacramentales de los que tenemos noticia, El auto de los Reyes Magos, con una puesta en escena en la que se implican buena parte de sus vecinos. Y, de tener que seleccionar algún otro ritual que destaque por su singularidad en los fríos días de invierno, tal vez tendríamos que referirnos a la fiesta de Santa Lucía en Villanueva del Duque, con el peculiar recorrido por las calles del pueblo de su hermandad al sonido del tambor, revoloteo de su bandera, el convite abierto a todos sus hermanos limitado a la sobriedad de los puñados de garbanzo tostados que toman de la cesta y el vino compartido en la misma templaera, y, en la noche de la víspera, el enorme candelorio de aulagas que se quema frente a la casa del capitán.

Pero, como era de esperar, es en primavera y verano cuando este sistema ritual eclosione con más vitalidad. Las cruces de mayo, festejadas en diferentes poblaciones, tienen una personalidad propia en la pequeña población de Añora: las cruces de piedra que jalonan calles y plazas, así como las habitaciones de algunas de sus casas, se cubren de laboriosos y barrocos
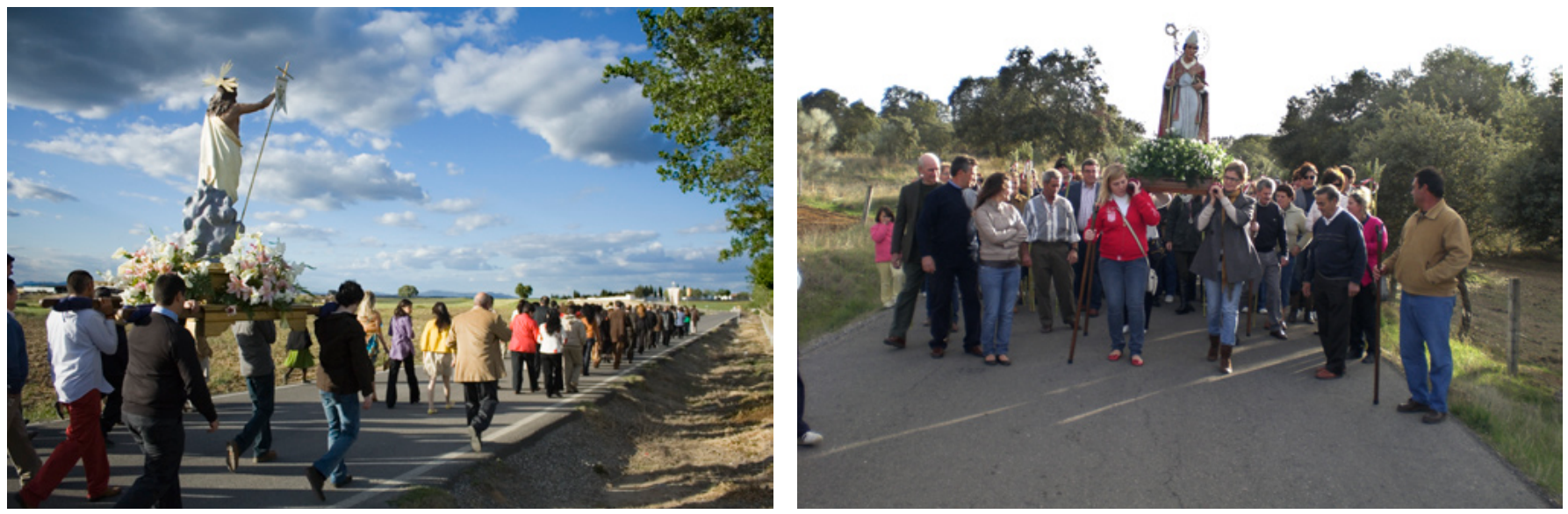
Semana Santa en Pozoblanco

| fotos Fondo Gráfico IAPH
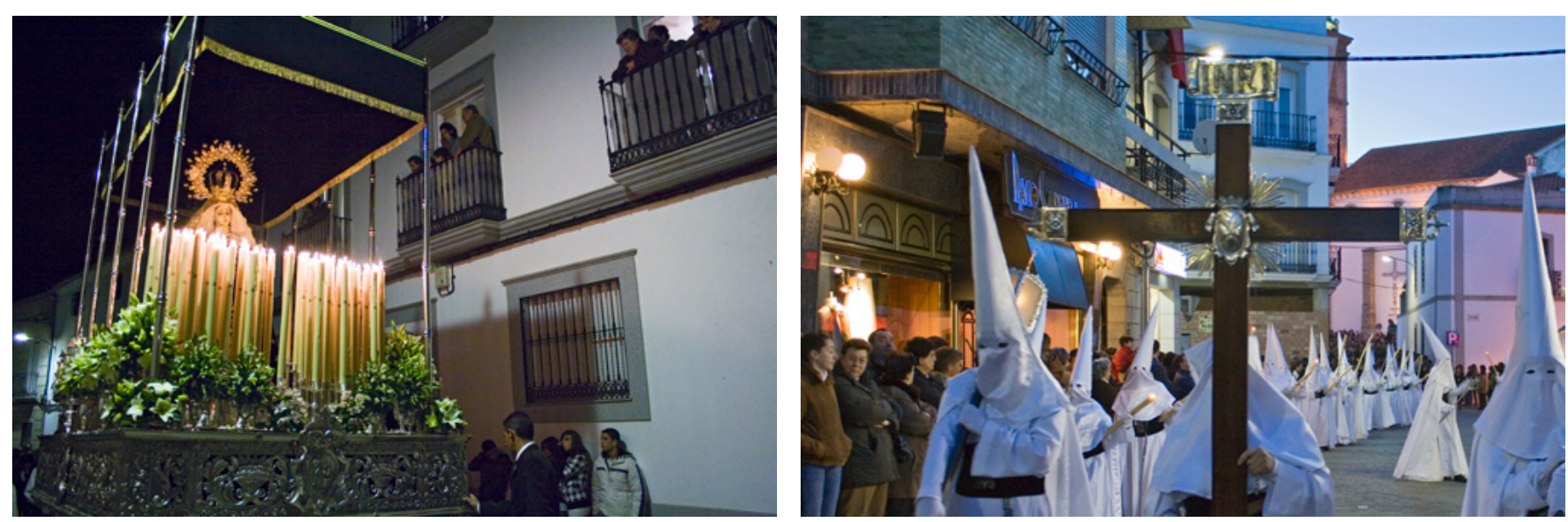

ornamentos que tienen por soporte humildes materiales de flores de papel, macetas, telas, etc.; y para conseguirlo, de nuevo la labor compartida de buena parte de su vecindario reseñando el sentido de comunidad que caracteriza a buena parte de los rituales de la comarca.

La Semana Santa, al menos de forma testimonial, no va a faltar en ninguna localidad. Si bien es en aquellas poblaciones que por razones históricas (Belalcázar) o de mayor capacidad demográfica (Hinojosa del Duque, Pozoblanco, Villanueva de Córdoba) han tenido o tienen una mayor riqueza de matices sociales, donde se manifieste con más brío en número de cofradías y peculiaridades etnográficas de algunas de sus puestas en escena: indumentaria de la cofradía del Santo Entierro en Hinojosa del Duque, soldados romanos (sayones) de Jesús Nazareno en Pozoblanco. Y el sábadodomingo de resurrección la vieja tradición de la quema de Judas se sigue practicando en Villanueva del Duque, Alcaracejos y Villanueva de Córdoba; en todos los casos son muñecos con los que de forma alegórica se invocan y destruyen aspectos negativos de nuestra sociedad, siendo especialmente cuidados y elaborados los marmotos de Villanueva de Córdoba. Pero se trata también de rituales que, lejos del inmovilismo que pudiera denotar la pervivencia de estas viejas tradiciones, han sabido adaptarse a nuevos tiempos, siendo ya un hecho generalizado el protagonismo activo de las mujeres tanto en su sistema asociativo como en los cortejos rituales; e incluso como costaleras en Hinojosa del Duque y Pozoblanco, una de las primeras en desarrollar esta práctica en la provincia de Córdoba.

Pero va a ser sobre todo en las expresiones rituales que tienen que ver con el mundo de las romerías donde el sistema ritual vigente en la comarca del valle de los Pedroches adquiere y manifieste su mayor singularidad. Creo que ninguna otra comarca andaluza ha preservado un patrimonio tan peculiar y rico como el conformado por las numerosas ermitas conservadas en 
el valle. En total existen cuarenta y siete ermitas, de las que veintiuna son rurales y otras ocho, aunque cercanas a los cascos urbanos, también se encuentran extramuros de las poblaciones. En su mayor parte datan de los siglos XIV al XVI, pero también, en un proceso compartido con otros lugares de Andalucía, se han construido en las décadas finales del s. XX (EI Viso, Fuente la Lancha, Conquista, Añora) al compás de la revitalización del significado simbólico que tienen las romerías en la cultura mediterránea, de ocasión de encuentro entre mundo rural y urbano, y de lugar y tiempo propicio para la concurrencia y autopercepción de las comunidades que las recrean.

Buena parte de estas ermitas, sobre todo las de carácter urbano o levantadas en las cercanías de los pueblos, acogen a santos encargados de proteger directamente a sus pobladores, o de contener las amenazas de epidemias y plagas que afecten a animales y cosechas: San Sebastián, San Antón, San Gregorio. Pero otras son destacados santuarios rurales que albergan a las imágenes marianas patronas de los respectivos pueblos, y dan lugar a rituales romeros de notable diversidad y riqueza etnográfica; sólo Añora y Dos Torres custodian a sus patronas en ermitas urbanas.

Cada una de las romerías que se celebran en el entorno de estas ermitas y santuarios son un mundo en sí mismas, y son muchas las razones para valorarlas y conocerlas. A la belleza de los parajes que acogen los santuarios (Virgen de las Veredas, de las Cruces, de Consolación, Santa Eufemia) hay que unir la capacidad de evocación de los caminos romeros entre cercas de piedra, sementeras y dehesas (Virgen de Luna, de Guía); las veladas de intensa convivencia comunal en los entornos de los santuarios (Virgen de la Antigua, de la Alcantarilla); o la singularidad de los procesos rituales que tienen lugar en la ermita o en los caminos (cruce del río Zújar en la romería de la Alcantarilla, juegos de banderas y descargas en las vírgenes de Luna y de Guía, engalanado de "jamugas" y "piostros" en la romería de Piedrasantas).
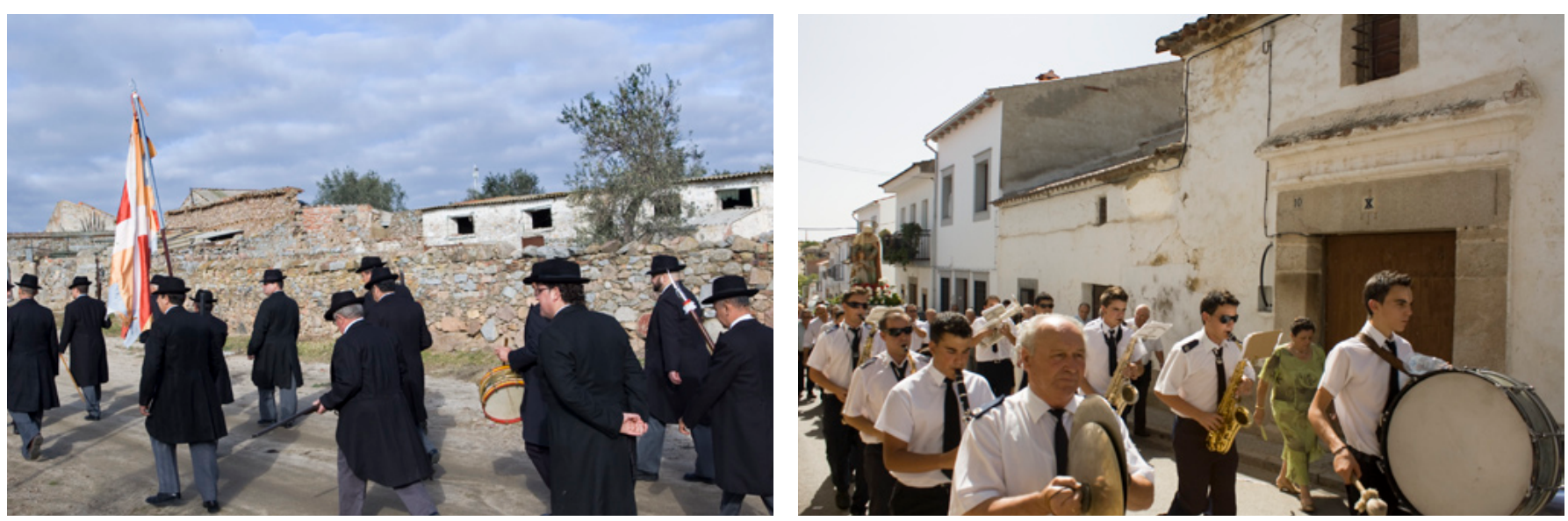


\section{Ermitas y devociones en el valle de los Pedroches}

\begin{tabular}{|c|c|c|c|c|c|c|}
\hline Población & Advocación & $E(1)$ & $\mathrm{R}(2)$ & $U(3)$ & $\mathbf{P}(4)$ & $\mathrm{R}(5)$ \\
\hline \multirow{2}{*}{ Alcaracejos } & Magdalena $(\mathrm{XVI})$ & & & & & \\
\hline & San Sebastián (XVI) & & & & & \\
\hline \multirow[t]{2}{*}{ Añora } & V. de la Peña (XVIII) & & & & & \\
\hline & San Martín (1996) & & & & & \\
\hline \multirow[t]{4}{*}{ Belalcázar } & V. de Gracia (Alcantarilla) (XV) & & & & (6) & \\
\hline & V de Consolación $(\mathrm{XVI})$ & & & & & \\
\hline & San Antón (XV) & & & & & \\
\hline & S. Sebastián (XIII) & & & & & \\
\hline \multicolumn{7}{|l|}{ Cardeña } \\
\hline Conquista & S. Gregorio (XX) & & & & & \\
\hline \multirow[t]{5}{*}{ Dos Torres } & S. Sebastián (XVI) & & & & & \\
\hline & V. de Loreto (XVI) & & & & & \\
\hline & S. Roque (XVI) & & & & & \\
\hline & S. Bartolomé (XVI) & & & & & \\
\hline & Santo Cristo de la Caridad (XVII) & & & & & \\
\hline El Guijo & V. de las Cruces (XVI) & & & & (7) & \\
\hline \multirow[t]{4}{*}{ El viso } & Santa Ana $(\mathrm{XVI} / \mathrm{XX})$ & & & & & \\
\hline & Cristo de las eras (XVI) & & & & & \\
\hline & San José (1993) & & & & & \\
\hline & V. de Vallehermoso (1990) & & & & & \\
\hline Fuente la Lancha & Santo Domingo (1999) & & & & & \\
\hline \multirow[t]{10}{*}{ Hinojosa del Duque } & V. de la Antigua (XIV) & & & & & \\
\hline & Santo Domingo (XIV) & & & & & \\
\hline & San Benito (XIV) & & & & & \\
\hline & San Isidro (XVIII) & & & & & \\
\hline & S. Gregorio (XVII) & & & & & \\
\hline & S. Sebastián (XIV) & & & & & \\
\hline & Santa Ana (XIII) & & & & & \\
\hline & Santo Cristo de las Injurias (XVIII) & & & & & \\
\hline & S. Bartolomé (XIV) & & & & & \\
\hline & V. del Castillo (XV) & & & & & \\
\hline \multirow[t]{4}{*}{ Pedroche } & V. de Piedrasantas (XVI) & & & & & \\
\hline & V. del Castillo (XVI) & & & & & \\
\hline & S. Sebastián (XV) & & & & & \\
\hline & Santa Lucía (XV) & & & & & \\
\hline \multirow[t]{4}{*}{ Pozoblanco } & V de Luna (XVI) & & & & (8) & \\
\hline & Cto de la Columna (XVIII) & & & & & \\
\hline & S. Antonio $(\mathrm{XVI})$ & & & & & \\
\hline & S. Gregorio (XVII) & & & & & \\
\hline \multirow[t]{2}{*}{ Santa Eufemia } & Santa Eufemia (XVI) & & & & & \\
\hline & Virgen de las Cruces (1898) b & & & & & \\
\hline \multirow[t]{3}{*}{ Torrecampo } & V. de Gracia (XIV) & & & & & \\
\hline & V. de las Veredas (XVI) & & & & & \\
\hline & Jesús Nazareno (XVI) & & & & & \\
\hline \multicolumn{7}{|l|}{ Villanueva de Córdoba } \\
\hline \multirow[t]{2}{*}{ Villanueva del Duque } & V. de Guía (XV) & & & & (9) & \\
\hline & San Gregorio (XVI) & & & & & \\
\hline \multirow[t]{2}{*}{ Villaralto } & Cristo de las Angustias (XVI) & & & & & \\
\hline & Santa Rita (1900) & & & & & \\
\hline
\end{tabular}

E(1) Extramuros (junto al casco urbano: cementerios, etc.);

R(2) Rural;

U(3) Urbana;

$\mathrm{P}(4)$ Devoción patronal;

$\mathrm{R}(5)$ Romería.

(6) En otros tiempos fue ermita supracomunal, a la que también acudía Hinojosa del Duque y, probablemente, la vecina población pacense de Monterrubio de la Serena.

(7) Supracomunal en el pasado. Fue ermita y devoción compartida entre el Guijo, Santa Eufemia y Torrecampo.

(8) Supracomunal. Es devoción patronal de Pozoblanco y Villanueva de Córdoba. Antaño también acudía Pedroche.

(9) Supracomunal. Acuden los pueblos de Hinojosa del duque, Fuente la Lancha, Dos Torres, Villanueva del Duque y Alcaracejos. Siendo patrona de los dos últimos. 
En este contexto habría que reseñar, por encima de lo que tienen de común estas ermitas, advocaciones y romerías con otros lugares de Andalucía, dos aspectos que sí particularizan a la comarca del valle de los Pedroches. El primero es la inusual importancia que han tenido y tienen las devociones supracomunales, reflejo de viejas prácticas de convivencia, concordias y conflictos por un territorio compartido. Así, la ermita de la Virgen de Gracia de la Alcantarilla (ubicada en un promontorio antaño fortaleza y población), hoy propiedad y albergue de la patrona de Belalcázar, fue en otros tiempos devoción compartida con Hinojosa del Duque y con la vecina población pacense de Monterrubio de la Serena; la peculiar ermita de la Virgen de las Cruces, próxima a las ruinas de una olvidada ciudad romana, hoy pertenece exclusivamente a EI Guijo, pero hasta el siglo XIX compartió con Santa Eufemia y Torrecampo santuario y devoción; la ermita de la Virgen de Luna ubicada en el corazón de antiguas tierras mancomunadas, y hoy propiedad de Pozoblanco, acoge a una imagen que sigue siendo la patrona de esta población además de la de Villanueva de Córdoba, y en el pasado también acudía a por ella Pedroche; por último, la ermita de la Virgen de Guía, hoy perteneciente a Villanueva del Duque pero ubicada en un lugar que, pese a estar en las afueras de la población, hasta el S. XIX fue territorio de Hinojosa del Duque, acoge a una imagen que continúa siendo patrona de Villanueva del Duque y Alcaracejos, pero que también cuenta con hermandades que acuden a por la Virgen en Fuente la Lancha, Dos Torres e Hinojosa del Duque.

En total once de las diecisiete poblaciones de la comarca estuvieron o siguen estando interrelacionadas entre sí a través de este complejo entramado simbólico. Pero no es sólo éste el elemento a reseñar, sino también el modo cómo se llevan a cabo estos rituales, inusual en el contexto andaluz y creo que peninsular: tanto la Virgen de Luna como la de Guía irán rotando a lo largo del año por las poblaciones que le rinden culto. Su territorio de gracia no se extiende desde el santuario que las acoge, como sería lo común, sino a partir de sí mismas en este deambular entre poblaciones.

Por último, el segundo rasgo al que nos venimos refiriendo es el peculiar sistema organizativo conformado por las hermandades militares. De forma muy sincrética, se caracterizan por la denominación militar que recibe su directiva (también suele denominarse al conjunto de la hermandad como soldadesca) constituida al menos (puede ser mucho más compleja) por un capitán, alférez y sargento, que van a portar como símbolos distintivos, respectivamente, bastón de mando, bandera y alabarda. Tampoco faltará como personaje imprescindible, vinculado al sargento, el tamborilero que irá marcando con el sonido del omnipresente tambor el proceso ritual.

A partir de estos rasgos primarios, existen otros elementos que los caracterizan, como el carácter rotativo (salvo en la Virgen de Luna de Pozoblanco) 

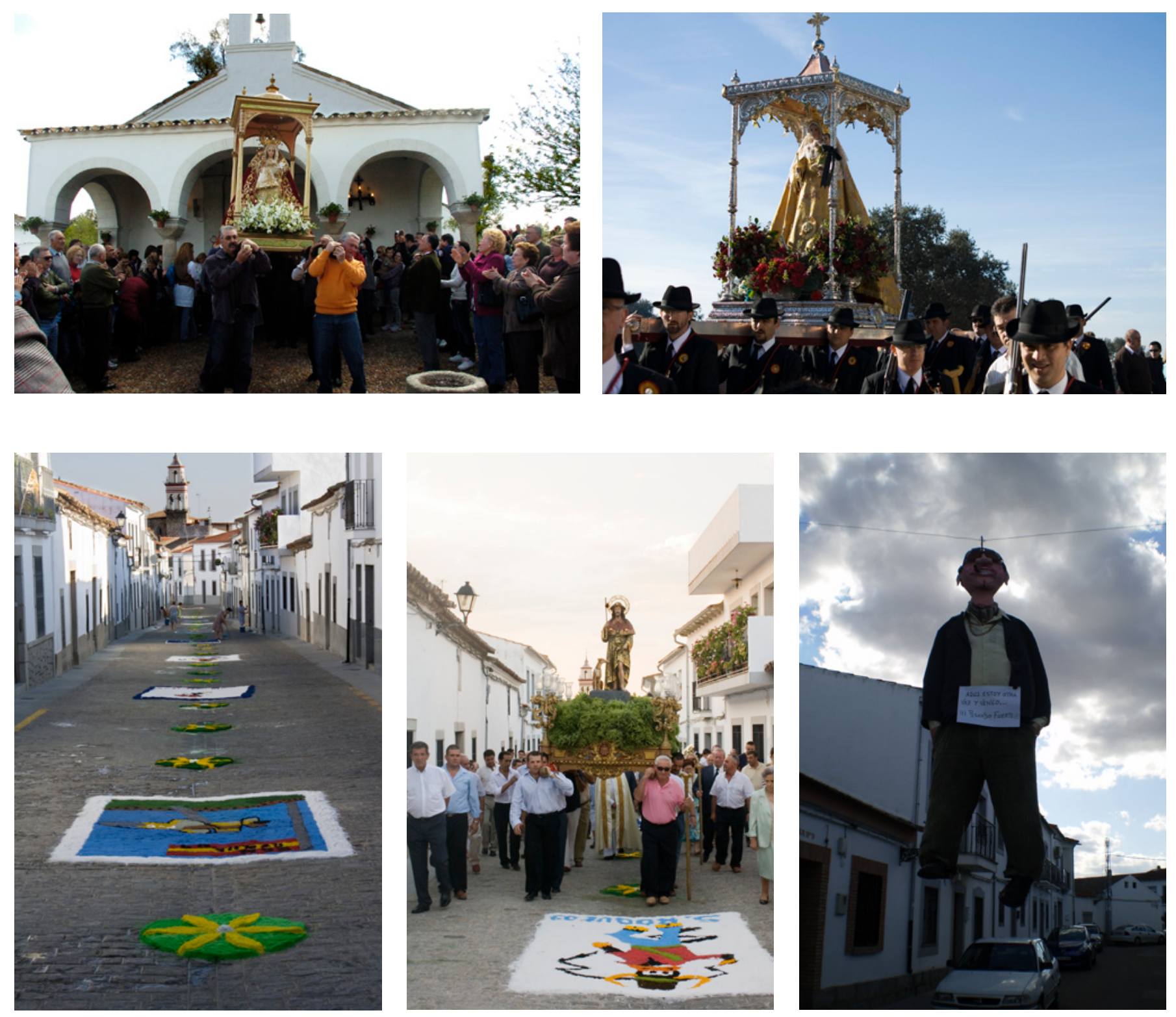

De izquierda a derecha y de arriba abajo:

Romería de la Virgen de las Cruces. El Guijo

Romería de la Virgen de Luna. Pozoblanco

de sus cargos, la importancia dada al comensalismo entre los hermanos (frecuentemente muy comedido en gastos y contenidos: garbanzos tostados, vino), y empleo de algunos de sus elementos para reseñar la vistosi-

Preparando las alfombras de San Roque dad de sus actos: revoloteo de banderas. Sobre este esquema, los matices etnográficos que particularizan cada uno de los rituales son muy variados: puede tratarse de hermandades de gloria (predominantes) o penitenciales, y en algunos casos, aun siendo penitenciales se transforman en otro momento del año en hermandades de gloria para celebrar sus actos de hermandad, como ocurre en Belalcázar, donde las cofradías de la Vera Cruz, Jesús

Procesión de San Roque. Dos Torres

| fotos Fondo Gráfico IAPH

Quema de Judas. Alcaracejos

| foto Miguel López Rísquez 
Nazareno y Cristo de la Salvación celebran sus festejos (convites, revoloteo de banderas, pasacalles) con motivo de, respectivamente, la Cruz de Mayo, el Corpus Christi y el Cristo de la Salvación.

En otras ocasiones la particularidad se encuentra en el modo como han transformado las sobrias insignias militares en floridos bastones de mando y alabardas (Santa Ana, Santa Eufemia, hermandades de Belalcázar). O bien se caracterizan por el empleo de escopetas para reseñar las diferentes fases del ritual. Y, excepcionalmente, por la extraña indumentaria, compuesta de mascota, chaleco, levita y pantalones negros, característica de las hermandades de la Virgen de Guía de Alcaracejos y Dos Torres y de Luna de Pozoblanco; complementada en los tres casos con las cartucheras y escopetas con las que realizan multitud de salvas a lo largo de los rituales. Con otro rasgo añadido más: todavía cinco de ellas (lo fueron en su mayor parte en el pasado) siguen manteniéndose como hermandades cerradas a las que sólo pueden pertenecer varones y en un número limitado.

Pero la particularidad de estos sistemas organizativos y rituales a los que dan vida no solo radica en las peculiaridades etnográficas a las que nos hemos referido, sino también en su excepcionalidad en el contexto de Andalucía. Actualmente perviven quince hermandades de esta tipología (nos consta la desaparición de al menos otras dos) actuando como base organizativa tanto de hermandades de gloria como penitenciales; $y$, dentro de éstas últimas, sosteniendo algunas de sus romerías y devociones patronales: Alcaracejos (Virgen de Guía), Villanueva de Córdoba y Pozoblanco (Virgen de Luna), Santa Eufemia (Santa Eufemia), El Viso (Santa Ana).

Fuera de esta comarca, en Andalucía, solo nos las volveremos a encontrar, en menor número, en algunas de las poblaciones de los territorios no menos limítrofes y fronterizos de las comarcas jienenses de la campiña Norte, sierra Mágina y sierra de Cazorla.

Para buscar sus orígenes, una vez más, tendríamos que seguir la senda que nos lleva hacia el norte, al corazón de las tierras castellanas. Y en este tránsito sí nos vamos a encontrar con otros ejemplos de similares características al cruzar las comarcas circunvecinas del valle manchego de la Alcudia y, en menor número, del extremeño valle de la Serena.

Pocos ejemplos como los que acabamos de describir pueden ser tan paradigmáticos a la hora de reseñar la condición de frontera cultural y, a la vez, de tierra de encuentro y paso de Andalucía que tuvo la comarca. Pero también todo lo dicho no hace sino confirmar el extraordinario patrimonio etnológico que conforma el sistema ritual y festivo del valle de los Pedroches. Un patrimonio donde pasado y presente se dan la mano cada año. 